\title{
Selected Metabolites Profiling of Staphylococcus aureus Following Exposure to Low Temperature and Elevated Sodium Chloride
}

OPEN ACCESS

Edited by:

Vincenzo De Feo,

University of Salerno, Italy

Reviewed by:

Evandro Leite de Souza,

Federal University of Paraíba, Brazil

Joanna Nakonieczna,

Medical University of Gdańsk, Poland

*Correspondence:

Mousa M. Alreshid

mo.alreshidi@uoh.edu.sa

Specialty section:

This article was submitted to

Food Microbiology,

a section of the journal

Frontiers in Microbiology

Received: 17 November 2019

Accepted: 07 April 2020

Published: 08 May 2020

Citation:

Alreshidi MM (2020) Selected

Metabolites Profiling

of Staphylococcus aureus Following

Exposure to Low Temperature and Elevated Sodium Chloride.

Front. Microbiol. 11:834. doi: 10.3389/fmicb.2020.00834
Mousa M. Alreshidi*

Department of Biology, College of Science, University of Ha'il, Ha'il, Saudi Arabia

Staphylococcus aureus is one of the main foodborne pathogens that can cause food poisoning. Due to this reason, one of the essential aspects of food safety focuses on bacterial adaptation and proliferation under preservative conditions. This study was aimed to determine the metabolic changes that can occur following the exposure of $S$. aureus to either low temperature conditions or elevated concentrations of sodium chloride $(\mathrm{NaCl})$. The results revealed that most of the metabolites measured were reduced in cold-stressed cells, when compared to reference controls. The major reduction was observed in nucleotides and organic acids, whereas mannitol was significantly increased in response to low temperature. However, when S. aureus was exposed to elevated $\mathrm{NaCl}$, a significant increase was observed in the metabolite levels, particularly purine and pyrimidine bases along with organic acids. The majority of carbohydrates remained constant in the cells grown under ideal conditions and those exposed to elevated $\mathrm{NaCl}$ concentrations. Partial least square discriminate analysis (PLS-DA) of the metabolomic data indicated that both, prolonged cold stress and osmotic stress conditions, generated cells with different metabolic profiles, in comparison to the reference controls. These results provide evidence that, when bacterial cells exposed to low temperatures or high concentrations of $\mathrm{NaCl}$, experience in situ homeostatic alterations to adapt to new environmental conditions. These data supported the hypothesis that changes in metabolic homeostasis were critical to the adaptive processes required for survival under alterations in the environmental conditions.

Keywords: S. aureus, metabolic profiling, stress response, purine and pyrimidine bases, food storage

\section{INTRODUCTION}

Staphylococcus aureus is both a commensal and a notable human pathogen, which causes a wide range of infections in nosocomial and community settings. The ubiquitous nature of this bacterium is partially attributed to its ability to sense changing environmental factors and respond accordingly by adapting to a wide range of environmental alterations (Onyango et al., 2012, 2013; Crompton et al., 2014; Alreshidi et al., 2015, 2016) as well as an impressive ability to resist 
innate immune defense mechanisms in the host resulting in systemic infections (Haste et al., 2012; Jongerius et al., 2012). However, the mechanisms behind the physiological adaptations of $S$. aureus under a diverse range of hostile conditions are still not clear. It has been hypothesized that changes in the patterns of metabolites and proteins are critical for its adaptation and infection initiation (Alreshidi et al., 2015, 2016). A study has revealed an adaptation mechanism of $S$. aureus under glucose limiting conditions by employed alterations in its metabolites and proteins (Liebeke et al., 2011). It was found that, when S. aureus was exposed to even small alterations in environmental conditions, it led to noticeable changes in the amino acid profiles, fatty acids and protein compositions (Crompton et al., 2014; Alreshidi et al., 2016). Therefore, it was concluded that alterations in metabolites and proteins facilitated the survival of $S$. aureus when exposed to confined nutrition in combination with higher concentrations of $\mathrm{NaCl}$. Another study on $S$. aureus demonstrated that on exposure to hydrogen peroxide $\left(\mathrm{H}_{2} \mathrm{O}_{2}\right)$ combined with various temperatures substantially affected the amino acid metabolites and the consumption of free amino acids in the media in comparison to reference control samples (Murphy et al., 2018). When S. aureus was grown at low temperature $\left(4^{\circ} \mathrm{C}\right)$, noticeable changes were observed in the structure of cell wall and size of the cells and colonies (Onyango et al., 2012, 2013). Small colony variants (SCVs) are sub-populations of bacterial cells which are characterized by reduced metabolic activity, pigmentation, and virulence factors (Tuchscherr et al., 2010; Proctor et al., 2014). Biofilm is a complex bacterial community embedded within an extracellular matrix adherent to a surface (Arciola et al., 2002; Adnan et al., 2011). SCVs occur during biofilm formation. Enhanced generation of SCVs and biofilm provide bacteria with the advantage of resistance against changes in environmental conditions (Singh et al., 2010; Mirani et al., 2015; Dubois-Brissonnet et al., 2016).

Low temperatures used in refrigeration and high $\mathrm{NaCl}$ concentrations are both used as food preserving techniques to prevent bacterial contamination, by making growth conditions sub-optimal, if not inhibitory, for most potential contaminants (Burgess et al., 2016). However, certain bacteria, such as S. aureus, have been shown to adapt, survive and even proliferate under these adverse conditions encountered in food production and storage, leading to a restricted shelf life of food products (Carrera et al., 2017). It has also been shown that, a different range of temperatures, combined with various environmental factors also led to altered metabolomic and proteomic responses (Alreshidi et al., 2016). At the bacterial cell level, a temperature decrease reduces the fluidity of cell membranes, which in turn affects active transport and protein secretion (Mykytczuk et al., 2007). Additionally, transcription and translation efficiency is reduced due to stabilization of DNA and RNA secondary structures (Chanda et al., 2010). Protein folding also becomes inefficient and ribosomes need to exhibit adaption for adequate function (Phadtare, 2004). A previous study showed that the exposure of $S$. aureus to low temperature resulted in substantial up-regulation of certain ribosomal proteins, citric acid and a significant reduction in a high number of amino acids (Alreshidi et al., 2015).
Staphylococcus aureus is considered to be an osmo-tolerant bacterium (Shebuski et al., 2000; Vilhelmsson and Miller, 2002a,b), however, little is understood about the mechanisms conferring high salt tolerance by the bacteria. Our recent study investigated amino acid metabolites and proteomic responses of $S$. aureus when incubated in a minimal medium supplemented with $5 \% \mathrm{NaCl}$. The results indicated significant alterations in amino acid concentrations and protein regulations (Alreshidi et al., 2019). However, to date this experimental design has yet to be adjusted to investigate nucleotides, nucleosides, organic acids and sugar alcohol levels in response to the conditions of low temperature and/or high $\mathrm{NaCl}$. Therefore, this study aims to characterize the metabolic changes (specifically in reference to carbohydrates; pyrimidine and purine bases; nucleosides and nucleotides) that occur as a result of low temperature $\left(4^{\circ} \mathrm{C}\right)$ and elevated sodium chloride (5\%) conditions. It is hypothesized that the exposure of $S$. aureus to conditions of low temperature and elevated $\mathrm{NaCl}$ induce significant alterations in its metabolic profiles.

\section{MATERIALS AND METHODS}

\section{S. aureus Strain Preservation and Storage}

Staphylococcus aureus used in the current study was isolated from patients who were suffering from chronic muscle pain (Butt et al., 1998). This bacterium was used in following investigations to study metabolic and proteomic adaptation to alterations in the environmental factors (Onyango et al., 2012, 2013; Alreshidi et al., 2015, 2016). The bacterial strain was grown as culture stock on horse blood agar (HBA) and preserved on sterile glass beads at $-80^{\circ} \mathrm{C}$ with a regular sub-culturing to maintain viability. This bacterium was checked frequently using $\mathrm{API}^{\mathrm{TM}}$ Staph biochemistry and through the amplification of 16S rRNA gene by polymerase chain reaction (PCR) (Brown et al., 2001).

\section{Bacterial Growth Conditions at Low Temperature $\left(4^{\circ} \mathrm{C}\right)$}

Overnight cultures $(50 \mathrm{ml})$ of $S$. aureus were grown in Tryptic Soy Broth (TSB) at $37^{\circ} \mathrm{C}$ with constant agitation (120 rpm). Eight flasks containing $95 \mathrm{ml}$ TSB culture media were inoculated with $5 \mathrm{ml}$ of overnight culture in $500 \mathrm{ml}$ conical flasks which were then incubated at $37^{\circ} \mathrm{C}$ with constant agitation $(120 \mathrm{rpm})$ for $3 \mathrm{~h}$. Four biological replicates were harvested at the midexponential phase of growth $(3 \mathrm{~h})$ and processed for analyses to represent the control samples. The remaining four cultures were kept at lower temperature of $4^{\circ} \mathrm{C}$ for 14 days. Cell viability and numbers were tested by the plating method and the identity was confirmed with API. The reference control samples and the coldtreated samples were harvested by centrifugation at $6500 \times g$ for $25 \mathrm{~min}$ at $4^{\circ} \mathrm{C}$. Harvested cells were then washed three times with phosphate buffered saline (PBS) to ensure the elimination of all residual TSB. The washed cells were immediately quenched using liquid nitrogen for lyophilization and subsequent extraction for metabolic analysis. 


\section{Bacterial Growth and Incubation Conditions With Additional of $5 \% \mathrm{NaCl}$}

Overnight cultures of $S$. aureus were grown in Tryptic Soy Broth (TSB) at $37^{\circ} \mathrm{C}$ with constant agitation $(120 \mathrm{rpm})$. Eight flasks containing $95 \mathrm{ml} \mathrm{TSB}$ culture media were inoculated with $5 \mathrm{ml}$ of overnight culture in $500 \mathrm{ml}$ conical flasks which were incubated at $37^{\circ} \mathrm{C}$ with constant agitation $(120 \mathrm{rpm})$ for $3 \mathrm{~h}$. Replicate cultures were harvested and washed three times using phosphate buffer saline (PBS) to ensure the elimination of TSB medium. Washed cells were then incubated in a defined minimal medium consisting of PBS with trace as described in Alreshidi et al. (2019). The incubation medium did not allow the cells replication but provided required elements and nutrients bases of energy and nitrogen that help bacterial cells to have active metabolism. The number of cells was assessed by the plating techniques to determine colony forming units (CFU) at initial and final times of incubation for both control and $\mathrm{NaCl}$ stressed samples.

\section{Metabolites Extraction}

Washed cells were lysed using snap-frozen and thawing technique 3 times and placed in a dryer machine overnight. Approximately 10-12 mg of lyophilised cells were resuspended with $10 \mathrm{ml}$ of $1: 1(\mathrm{v} / \mathrm{v})$ of cold methanol/water stored at $-20^{\circ} \mathrm{C}$ and mixed thoroughly. The methanol/water lyophilised cell slurries were snap frozen in liquid nitrogen and placed in freezer at $\left(-20^{\circ} \mathrm{C}\right)$ for $30 \mathrm{~min}$ for a process of slow thawing. Metabolites were then separated from the cell debris by centrifugation at $6,500 \times g$ for $25 \mathrm{~min}$. The supernatants containing the metabolites were dried using a centrifugal vacuum drier (CentriVap, LABCONCO, VWR) (Alreshidi et al., 2015).

\section{Metabolites Identification and Quantification}

Dried cytoplasmic metabolites including carbohydrates and purine and pyrimidine metabolites were evaluated by forming the methoxy-amine-trimethylsilyl (TMS) derivatives by reacting the dry extracts with Methoxyamine-HCL (MOX) and Bis(trimethylsily) trifluoroacetamide (BSTFA). Lyophilised metabolites were mixed with $50 \mu \mathrm{l}$ of MOX vortexed very well, and then heated at $60^{\circ} \mathrm{C}$ for $30 \mathrm{~min}$. Samples were then allowed to cool and subsequently $150 \mu \mathrm{l}$ of BSTFA was added to each sample, vortexed and heated at $100^{\circ} \mathrm{C}$ for $60 \mathrm{~min}$. Derivatised samples were analyzed by auto-sampler gas chromatography (Agilent, Hewlett-Packed 5973) coupled with mass spectrometry. The injection volume was $1 \mu \mathrm{l} / \mathrm{sample}$ and flow rate was $0.5 \mathrm{ml} /$ min. Metabolites in the chromatogram were identified on the basis of matching their mass spectra and retention time indices with data in use-generated mass spectral libraries generated from reference standards.

\section{Metabolic Profile Data Processing and Statistical Analysis}

The acquired metabolite data obtained from GC-MS were exported to an Excel $^{\circledR}\left(\right.$ Microsoft $\left.^{\circledR}\right)$ sheet. The exported data were then imported to STATISTICA (6, StatSoft) (ANOVA) to identify the metabolites that were significantly altered in response to lower temperature and elevated $\mathrm{NaCl}$. Multivariate statistical analysis was then preformed using the partial least squares discriminant analysis (PLS-DA) as implemented in MetaboAnalyst 4.0 online package to better identify classification and clustering (www. metaboanalyst.ca) (Xia et al., 2009). The data were preprocessed by the sum normalization, with mean-centered and auto-scaling before creating the model. The model complexity and validity were assessed by cross-validation including the goodness-of-fit parameter (R2) and the goodness-of-predication parameter (Q2).

\section{Metabolic Pathway and Enrichment Analyses}

Metabolic pathway analysis, which combines Metabolite Set Enrichment Analysis (MSEA) and Metabolomic Pathway

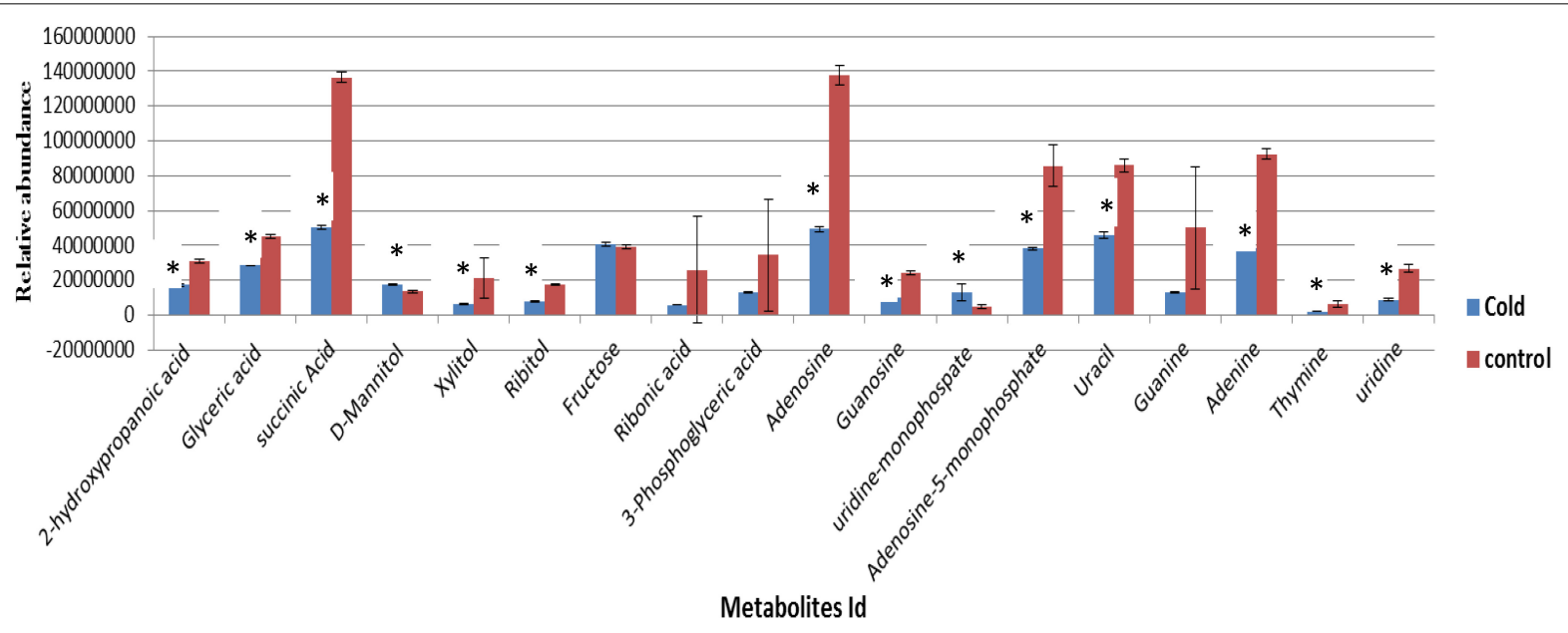

FIGURE 1 | The relative abundances of cytoplasmic metabolites extracted from the cells grown to a mid-exponential phase of growth at $37^{\circ} \mathrm{C}$ (control, $n=4$ ) compared with equivalent sets of the cells that were subsequently exposed to lower temperature of $4^{\circ} \mathrm{C}(\mathrm{Cold}, n=4)(\mathrm{mean} \pm \mathrm{SD}, p<0.05)$. Significantly altered metabolites. 
Analysis (MetPA) was conducted using MetaboAnalyst 4.0 (Xia et al., 2009). GC-MS data were submitted to metaboAnalyst specifically to MetPA and MSEA with annotation based on compound names. Accepted metabolites were manually checked by different databases including KEGG and pubChem databases. The pathway library of $S$. aureus N315 was selected for pathway analysis. Metabolite sets enrichment was preformed according to KEGG database which contains 84 metabolite sets, and at least 2 compounds represent each metabolite sets.

\section{RESULTS}

\section{Metabolites Analysis at Low Temperature $\left(4^{\circ} \mathrm{C}\right)$ for 2 Weeks}

Eight biological replicates of $S$. aureus were grown to the mid-exponential phase of growth under ideal conditions. Four biological replicates were collected for analysis to represent the control samples to compare with the remaining four biological replicates which were incubated at $4^{\circ} \mathrm{C}$ before harvesting for metabolic analysis. The cell numbers for replicates harvested at $37^{\circ} \mathrm{C}$ were $5.7 \pm 0.9 \times 10^{7}$ and the cell numbers for cold stressed samples were $5.5 \pm 0.4 \times 10^{7}$. The results indicated that no significant reduction in cell numbers following incubation in cold temperatures $\left(4^{\circ} \mathrm{C}\right)$. Metabolites analysis by GC-MS indicated that the cytoplasmic metabolites in cold-stressed replicates had numerous changes in the profile compositions in comparison to reference control samples (Figure 1). A significant decrease in purine and pyrimidine bases, nucleosides and organic acids abundances was observed in cells incubated at low temperature in comparison to samples grown under ideal conditions representing considerable changes in metabolic homeostasis. Among the identified carbohydrates, a significant reduction of two sugar alcohols including ribitol and xylitol was observed, but mannitol was significantly increased (Figure 1).

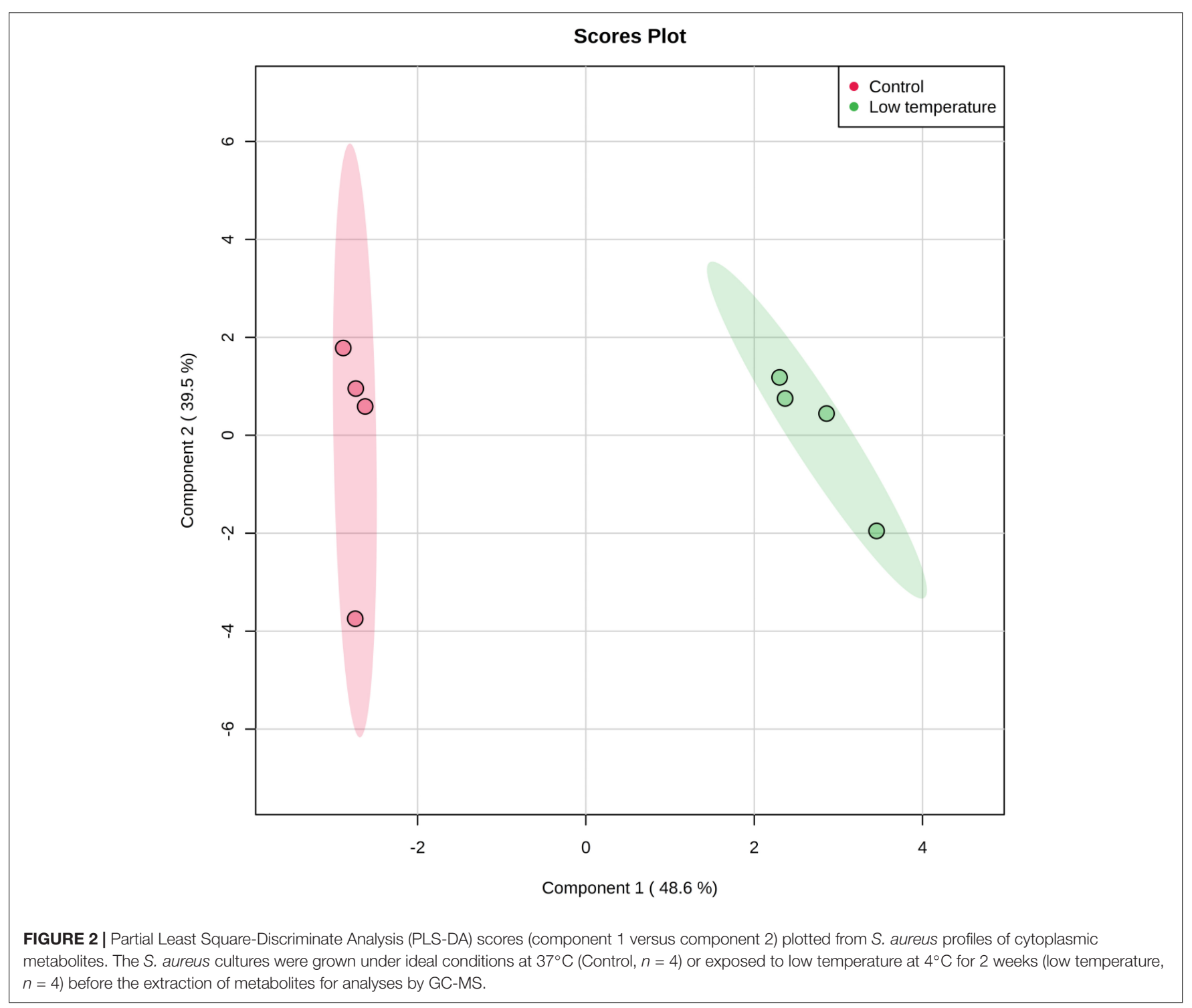




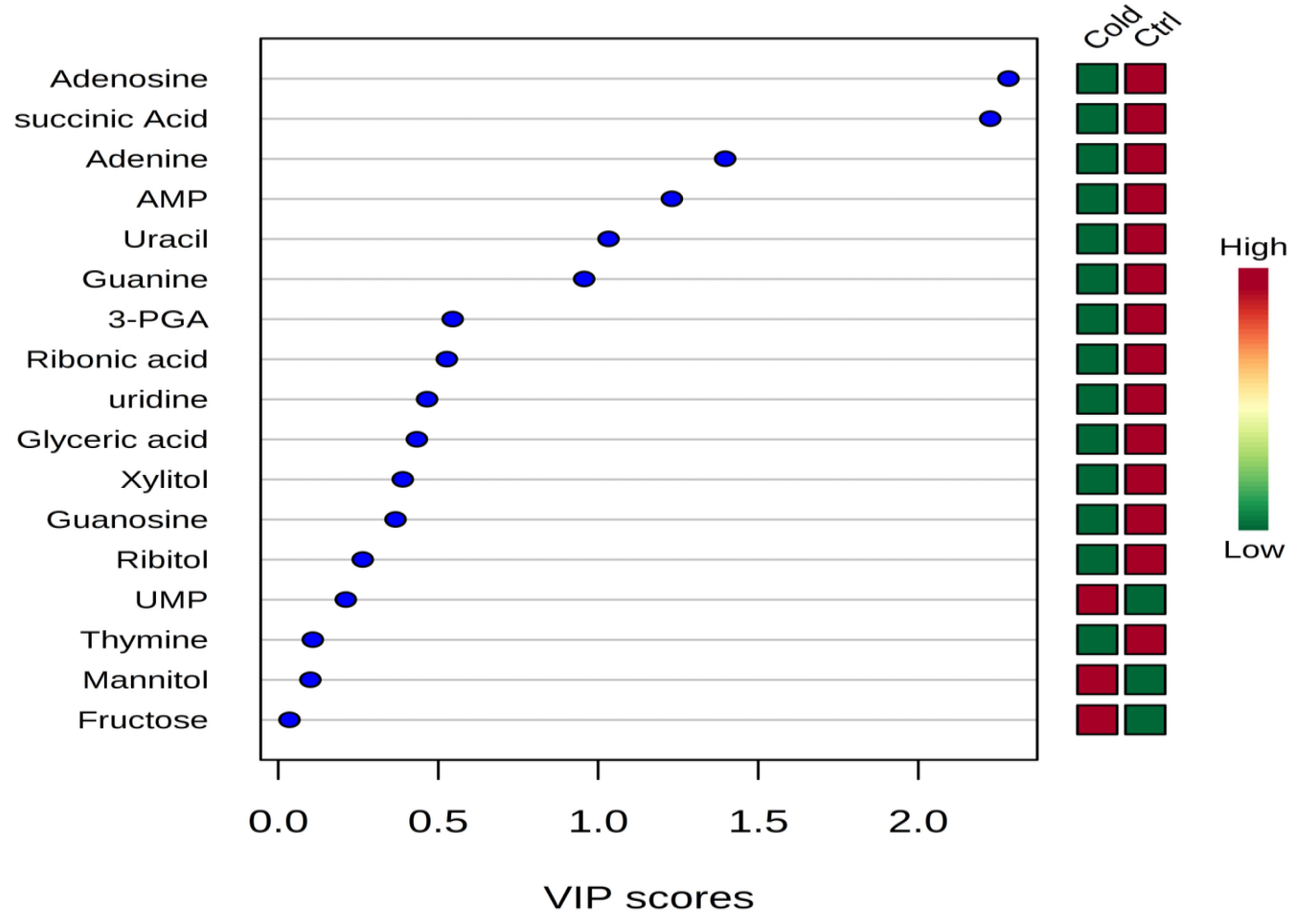

FIGURE 3 | Variable importance in projection (VIP) scores indicating the top important metabolites contributing to the separation of metabolic profiles in control replicates vs. cold stressed samples. The relative abundance of metabolites is indicated by a colored scale from green to red representing the low and high, respectively.

The cytoplasmic metabolite compositions from the cells grown under optimal conditions and those exposed to lower temperature of $4^{\circ} \mathrm{C}$ for 2 weeks were further investigated using partial least square discriminate function (PLS-DA) to provide important insights into metabolic profiles of two groups. The PLS-DA analysis rendered a two-component model as calculated by cross-validation (CV). The PLS-DA analysis scores for control and stressed samples showed two obvious clusters separated by component 1 scores where the cytoplasmic metabolites analyzed from control samples positioned at the negative component 1 and the treatment samples positioned at the positive side of component 1 (Figure 2). Explanation of $87.4 \%$ of the analyzed data was accomplished (i.e., $R 2=0.97$ and $Q 2=0.95$ ) and the eigenvalue for component 1 was 14.5 as compared to 2.4 for component 2 . The great variation between the eigenvalues point out that most of the explained data differences associated with clustering of the cold-stressed samples from untreated cells. In corollary, as shown in PLS-DA graph, metabolites analyzed from untreated cells were clustered separately from the cells exposed to low temperature suggesting the presence of different metabolic patterns in the two treatment regimens. The cells incubated at lower temperature of $4^{\circ} \mathrm{C}$ for 2 weeks were characterized via a great reduction in the abundances of measured metabolites in particular succinic acid and adenosine as shown in Figure 3.

The cytoplasmic metabolites that were contributing to the classification of control and cold-stressed samples were also identified using the variable importance in projection (VIP) scores (Figure 3). Metabolites with greater VIP scores are more important in contributing to the separation between the two groups, while those with smaller VIP scores have less influence to the model. Metabolites such as adenosine, succinic acid, adenine adenosine-mono-phosphate (AMP) had VIP score greater than 0.1 indicating that these metabolites played an essential role in the discrimination of metabolic profiles of cells grown under ideal conditions and those exposed to lower temperature of $4^{\circ} \mathrm{C}$ (Figure 3).

\section{Metabolic Enrichment and Metabolic Pathway Analyses}

The metabolite set enrichment and metabolic pathway analyses were performed using MetaboAnalyst 4.0 to find out the most altered metabolic pathways following incubation in prolonged cold environment. The pathway impact value was calculated from topology pathway analysis, those with score higher than 0.10 was considered as a significant metabolic pathway. The analysis identified 10 matched pathways, including purine metabolism, pyrimidine metabolism, TCA cycle, butanoate metabolism, propionate metabolism, pyruvate metabolism, glycolysis and gluconeogenesis, fructose and mannose metabolism, pentose glucose interconversion, amino sugar and nucleotide sugar metabolism, sulfur metabolism, glyxolate decarboxylic 
A

\section{Metabolite Sets Enrichment Overviev}

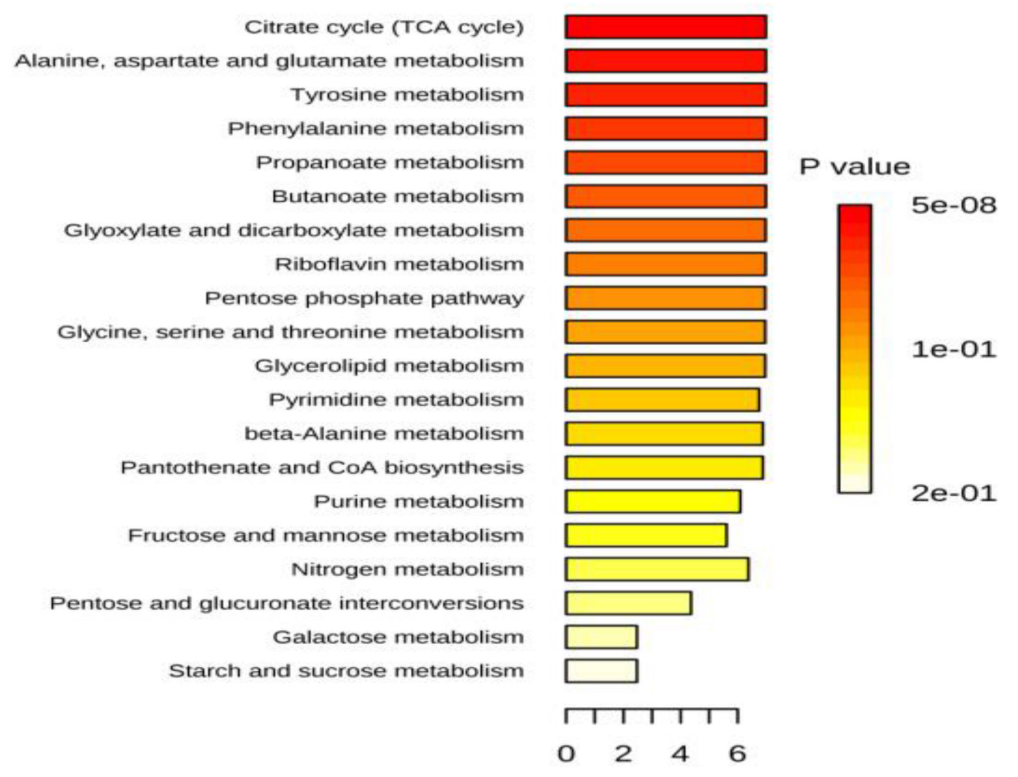

Fold Enrichment

B

Butanoate Metabolism Citrate cycle (TCA cycle)

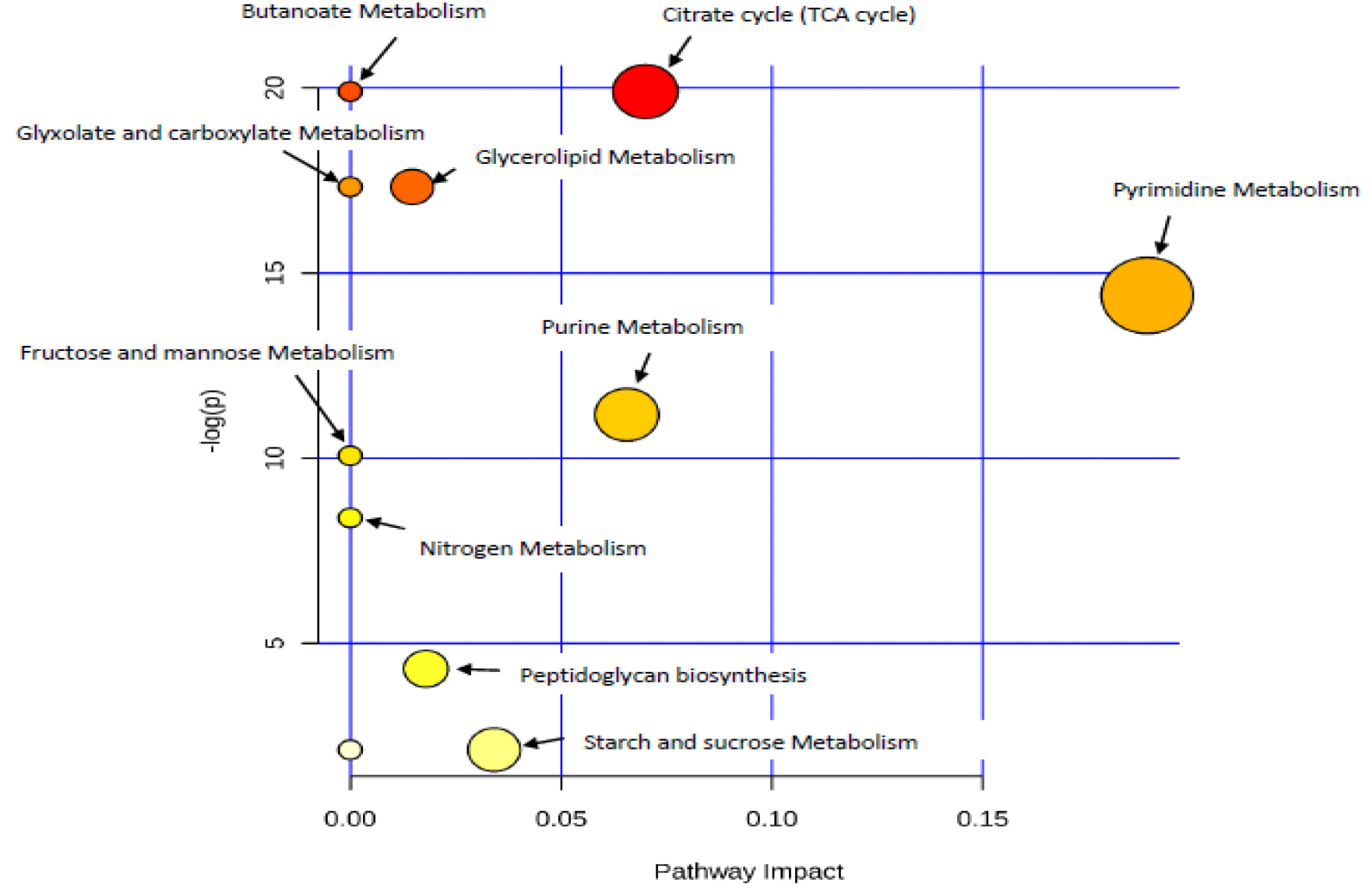

FIGURE 4 | (A) metabolic set enrichment using metabolite concentrations showing the most enriched pathways in response to lower temperature of $4^{\circ} \mathrm{C}$.

(B) Pathway impact analysis. All the matched pathways are shown as circles. The color and size of each circle is based on $p$-value and pathway impact value, respectively. Colors of the circle based on $p$-values. The darker colors indicate more significant pathway $(p<0.05)$. 


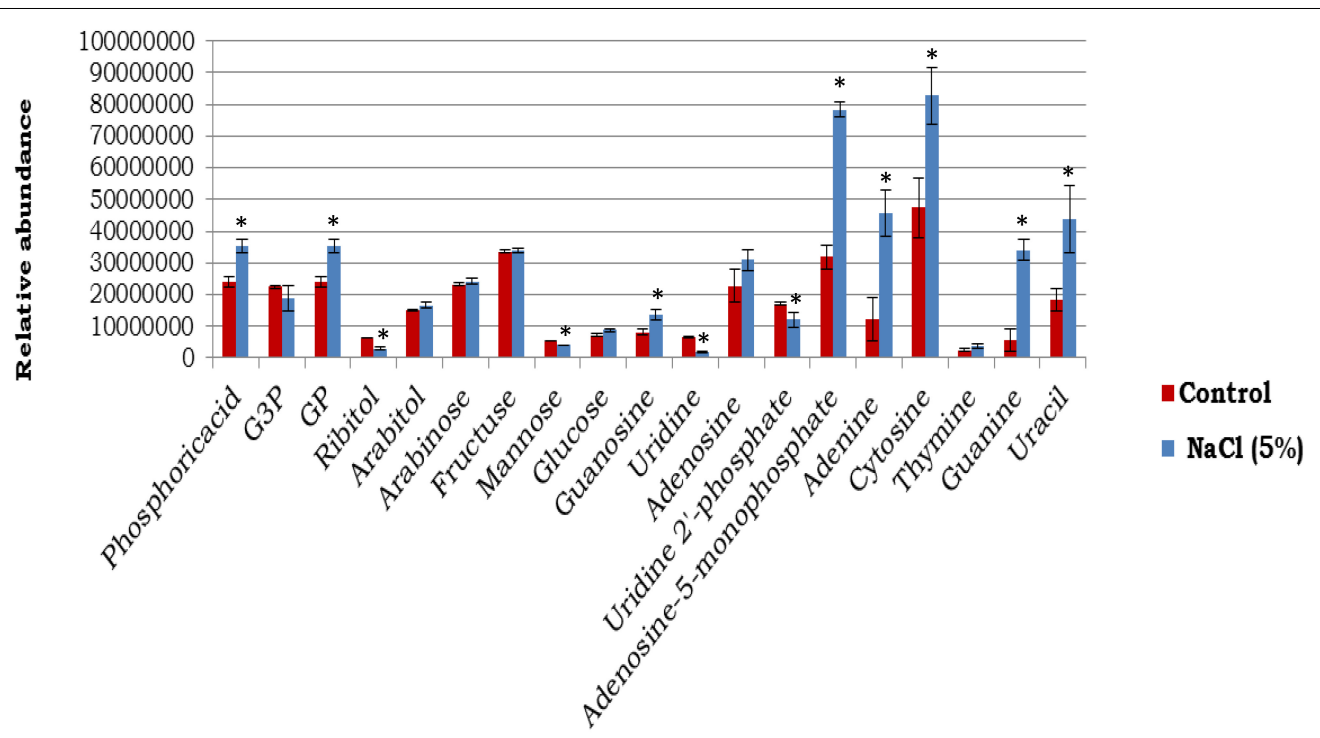

\section{Metabolites}

FIGURE 5 | The abundances of cytoplasmic metabolites extracted from cells incubated in a defined medium (reference control, $n=4$ ) compared with equivalent sets of cells that were incubated in the defined medium supplemented with $5 \% \mathrm{NaCl}(n=3)$ (mean $\pm \mathrm{SD}) .{ }^{*} p<0.05 .{ }^{*}$ Signicantly altered metabolites.

metabolism, glycine serine and threonine metabolism and glycerolipid metabolism (Figure 4B). However, six metabolic pathways were significantly altered due to cold treatment, including TCA cycle, glycerolipid metabolism, pyrimidine metabolism, purine metabolism, peptidoglycan biosynthesis (Figure 4B). The quantitative enrichment analysis (MESA) was used to determine the major perturbed pathways affected in cold stressed samples (Figure 4A). Twenty biochemical pathways were identified by the analysis, seven of which were significantly affected by the cold treatment $(p<0.05)$ including citrate cycle, alanine-aspartate and glutamate metabolism, tyrosine metabolism, phenylalanine metabolism, propionate metabolism, butanoate metabolism, glyoxylate and decarboxylate metabolism $(p<0.05)$.

\section{Metabolites Analyses at Elevated $\mathrm{NaCl}$ $(5 \%)$}

The number of cells was assessed by the plating techniques to determine colony forming units (CFU) at initial time of incubation for both control and $\mathrm{NaCl}$ stressed samples, which produced values of $5.5 \pm 0.6 \times 10^{8}$ and $5.8 \pm 0.8 \times 10^{8}( \pm S D)$, respectively. At the final time of incubation the cell numbers for control and $\mathrm{NaCl}$ stressed samples were $5.3 \pm 0.5 \times 10^{8}$ and $5.6 \pm 0.9 \times 10^{8}( \pm S D)$, respectively. These results suggested that no significant alterations in the cell numbers occurred over the period of incubation. The metabolic analysis of cytoplasmic extract identified 19 metabolites in both reference control and osmotic stress $(5 \% \mathrm{NaCl})$ samples (Figure 5). Thirteen of these metabolites had undergone statistically relevant changes, whereas seven metabolites did not display any alterations in their abundance when the cells were incubated at an additional $5 \% \mathrm{NaCl}$, compared with reference control samples.
Sugar alcohols, including ribitol, were significantly decreased in response to osmotic stress, but arabitol remained unchanged. Glucose was increased, but fructose did not show any differences among the groups. Purine and pyrimidine bases significantly increased when cells were exposed to elevated $\mathrm{NaCl}$, with the exception of thymine, which remained unchanged in both groups. Guanosine levels considerably increased while uridine significantly decreased in response to osmotic stress (Figure 5).

The cytoplasmic metabolic profiles from reference control and $\mathrm{NaCl}$-treated cells were further evaluated using partial least square discriminate function (PLS-DA). The PLS-DA analysis rendered a two-component model as validated by crossvalidation $(\mathrm{CV})$. The PLS-DA analysis scores for cells grown under ideal conditions and those incubated with additional of $5 \% \mathrm{NaCl}$ revealed two obvious clusters separated by component 1 scores where the cytoplasmic metabolites analyzed from control replicates placed at the positive component 1 and the $\mathrm{NaCl}$ treatment samples placed at the negative side of component 1 (Figure 6). Clarification of $92.1 \%$ of the input data was achieved (i.e., $R 2=0.93$ and $Q 2=0.85$ ) and the eigenvalue for component 1 was 12.5 as compared to 2.8 for component 2 . The great difference between the eigenvalues indicated that most of the accomplished data variations associated with clustering of the $\mathrm{NaCl}$-stressed replicates from unstressed cells. In importance, as displayed in PLS-DA graph, metabolites analyzed from control cultures were gathered separately from the cells incubated with additional of 5\% $\mathrm{NaCl}$ suggesting the presence of different metabolic profiles in the two groups. The cells treated with $5 \% \mathrm{NaCl}$ were characterized via a general increase in the level of nitrogenous bases, while the control samples were described by an overall reduction in the metabolite levels with an exception of mannose and ribitol which were relatively increased. 


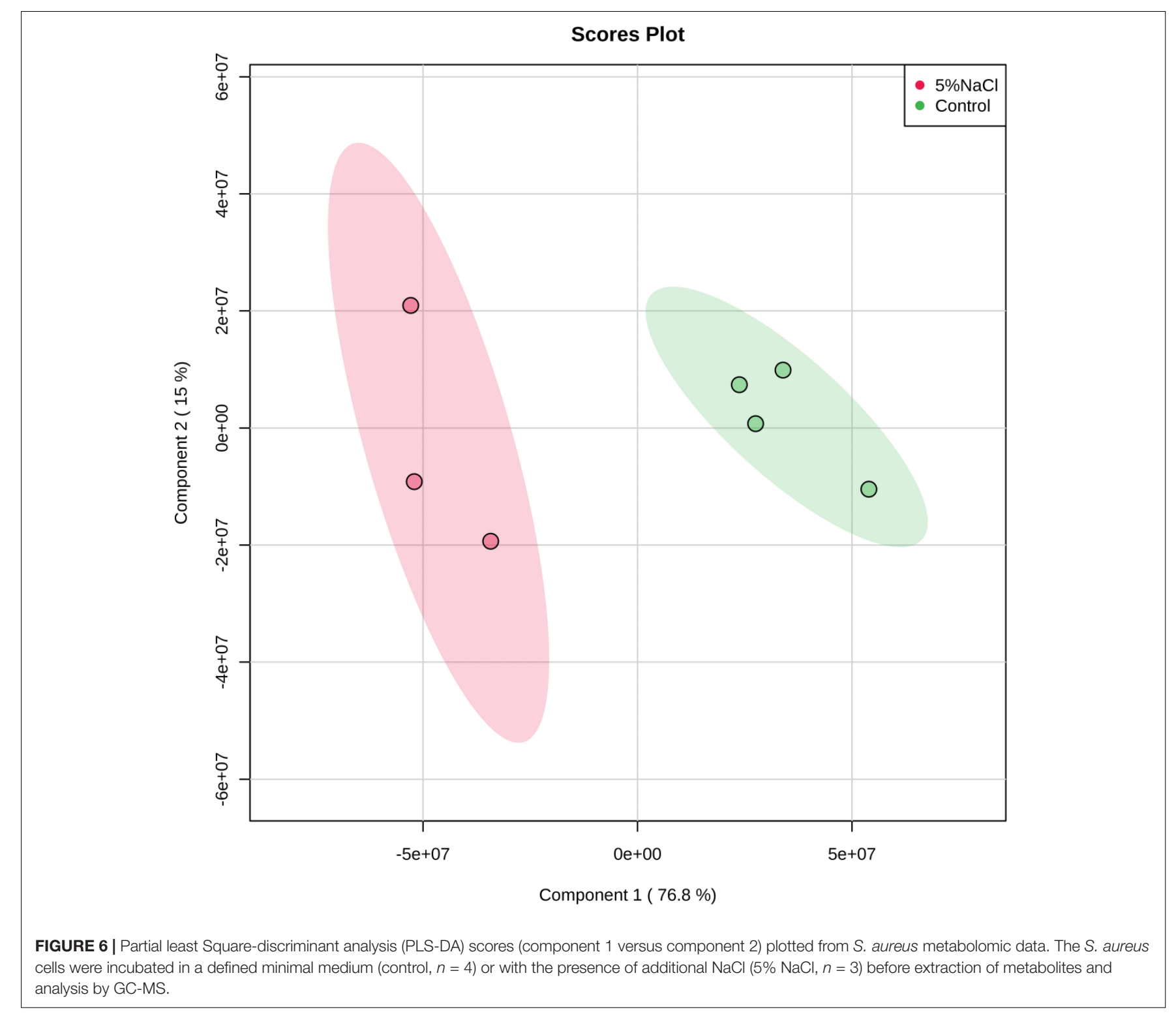

Variable importance in projection analysis was conducted to determine the top metabolites contributing to the variation of metabolic profiles of control and $\mathrm{NaCl}$ treatment samples (Figure 7). Metabolites with a VIP score of 1.0 have been considered as significantly contributed to the differences between the two groups. As shown in Figure 7, adenosinemonophosphate (AMP), adenine, guanine, uracil and cytosine were the most metabolites providing the classification between the cells grown under ideal conditions and those incubated with additional of $5 \% \mathrm{NaCl}$.

\section{Metabolic Enrichment and Metabolic Pathway Analyses}

Metabolic set enrichment overview revealed that analyzed metabolites were involved in the perturbation of 14 metabolic pathways due to osmotic pressure (Figure 8A). Out of these, five pathways were found to be the most affected during the incubation in elevated $\mathrm{NaCl}$ (5\%), including pentose and glucuronate interconversions, riboflavin metabolism, purine metabolism, beta-Alanine metabolism, pantothenate and CoA biosynthesis. Metabolic pathway analysis indicated that seven pathways were differentially regulated in response to osmotic stress (Figure 8B), two of which were significantly enriched including purine and pyrimidine metabolism.

\section{DISCUSSION}

The results from the present study revealed that the profiles of cytoplasmic metabolites observed in S. aureus grown under ideal conditions were different to those observed in cells grown under lower temperature of $4^{\circ} \mathrm{C}$ or elevated $\mathrm{NaCl}(5 \%)$. It was obvious that the demands for cytoplasmic metabolites altered following 
exposure to variations in the environmental conditions including, temperature and osmolality. Metabolites represent important precursors for the biosynthesis of nucleic acids, lipids and cell wall constituents as well as they play an important role in the metabolic homeostasis and cell integrity.

Metabolic analysis showed a general reduction in the metabolite abundances of the cells incubated at $4^{\circ} \mathrm{C}$ for 2 weeks compared with reference control samples grown under optimal conditions. However, the levels of these metabolites were different, which presumably reflected differential metabolic demands. Reduced metabolites in the cytoplasm of bacterial cells may represent slower metabolic rates in the cytoplasm. This would represent an essential way in adjusting the cellular homeostasis under changes in the environmental parameters. A Prior investigation revealed that $S$. aureus had reduced the levels of amino acids and glycolysis enzymes following exposure to lower temperature (Alreshidi et al., 2015). Recent study demonstrated that alterations in environmental conditions including variations in temperature and osmolality led to variations of amino acid uptake and release of $S$. aureus (Alreshidi et al., 2020).

It is not yet clear why mannitol significantly increased in cells exposed to cold stress whereas other carbohydrates either did not change or significantly reduced. Mannitol is synthesized from glucose and has been established to have an important role as an osmoprotectant in many bacteria including $S$. aureus (Edwards et al., 1981; Kets et al., 1996; Sand et al., 2013; Zahid et al., 2015). The cytoplasmic mannitol abundance was reported to play vital roles in response to high temperature and salinity, and pathogenicity in fungi (Chaturvedi et al., 1996; Calmes et al., 2013; Nguyen et al., 2019). The consumption of mannitol by S. aureus was shown to be essential to combat human skin antimicrobial fatty acids (Kenny et al., 2013). Also unexpected production of uridine monophosphate (UMP) was also noted in the cells stored in lower temperature for 2 weeks. This high production of UMP was possibly associated with the high requirement to synthase a thicker cell wall. A pervious study revealed that $S$. aureus had a thinker cell wall in response to prolonged cold stress compared with cells harvested at $37^{\circ} \mathrm{C}$ (Onyango et al., 2012, 2013).

Metabolic pathway and enrichment analyses revealed six biochemical pathways altered following exposure to lower temperature suggesting theses pathways were essential in combating the stress. Most of these metabolic pathways were involved in the energy production. The most affected metabolic pathway was citric acid cycle; this may suggest the lower energy production by cells exposed stress to minimize the energy during the stressful conditions. The substantial alteration in purine and pyrimidine pathways was represented by the significant reduction in their metabolites. The reductions in these metabolites may indicate the consumption of these metabolites to produce proteins to combat the cold stress. Our prior investigation showed that cold stress led to significant increase in nine ribosomal proteins and a substantial decrease in the majority of amino acids (Alreshidi et al., 2015). An earlier study showed that, the abundance of nucleotides was reduced

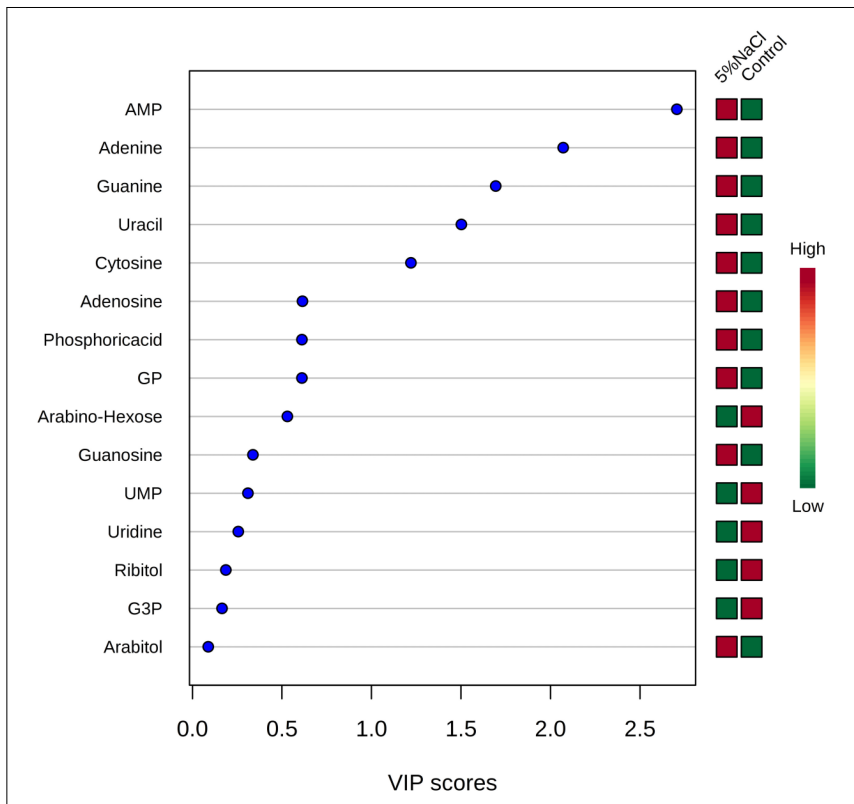

FIGURE 7 | Variable importance in projection (VIP) scores for the top metabolites contributing to variation in metabolic profiles of controls vs. cold treatment samples. The relative abundance of metabolites is indicated by a colored scale from green to red representing the low and high, respectively.

ten-folds in lactic bacteria when grown in lactose medium (Kilstrup et al., 2005).

Succinic acid was one of the metabolites that greatly contributed to the classification of metabolic profiles in control and cold treatment samples as depicted by PLS-DA plot (Figure 3) which was remarkably decreased in cells exposed to cold stress. The reduction in succinic acid may characterize an effective mechanism to conserve and maintain lower metabolic levels, as it plays an important role in energy production and donation (Vandecasteele et al., 2004; Kilstrup et al., 2005). The general reduction associated with the key metabolites involving in the energy synthesis could be linked with slower metabolism which is a common mechanism used by bacteria to adapt and facilitate survival during stress (Onyango et al., 2012). It could also suggest the utilization of these metabolites in the synthesis or conversion to other compounds to develop the adaptation processes in response to environmental stresses (Dorries and Lalk, 2013).

The exposure of $S$. aureus to osmotic stress led to an increase in the majority of the identified metabolites, in particular purine and pyrimidine bases. This increase may represent a conservation and survival mechanism in response to osmotic stress, as a result of the inhibition of physiological processes, including DNA replication, that occurs due to sudden plasmolysis (Csonka, 1989). It has been suggested that purine metabolites may provide stress protection in plants (Watanabe et al., 2014). Similar results were obtained when the effects of osmotic stress was demonstrated on Salmonella, with significantly elevated levels of intracellular metabolites, including purines and pyrimidines (Csonka, 1989; Burgess et al., 2016). This finding is thus consistent with current findings 


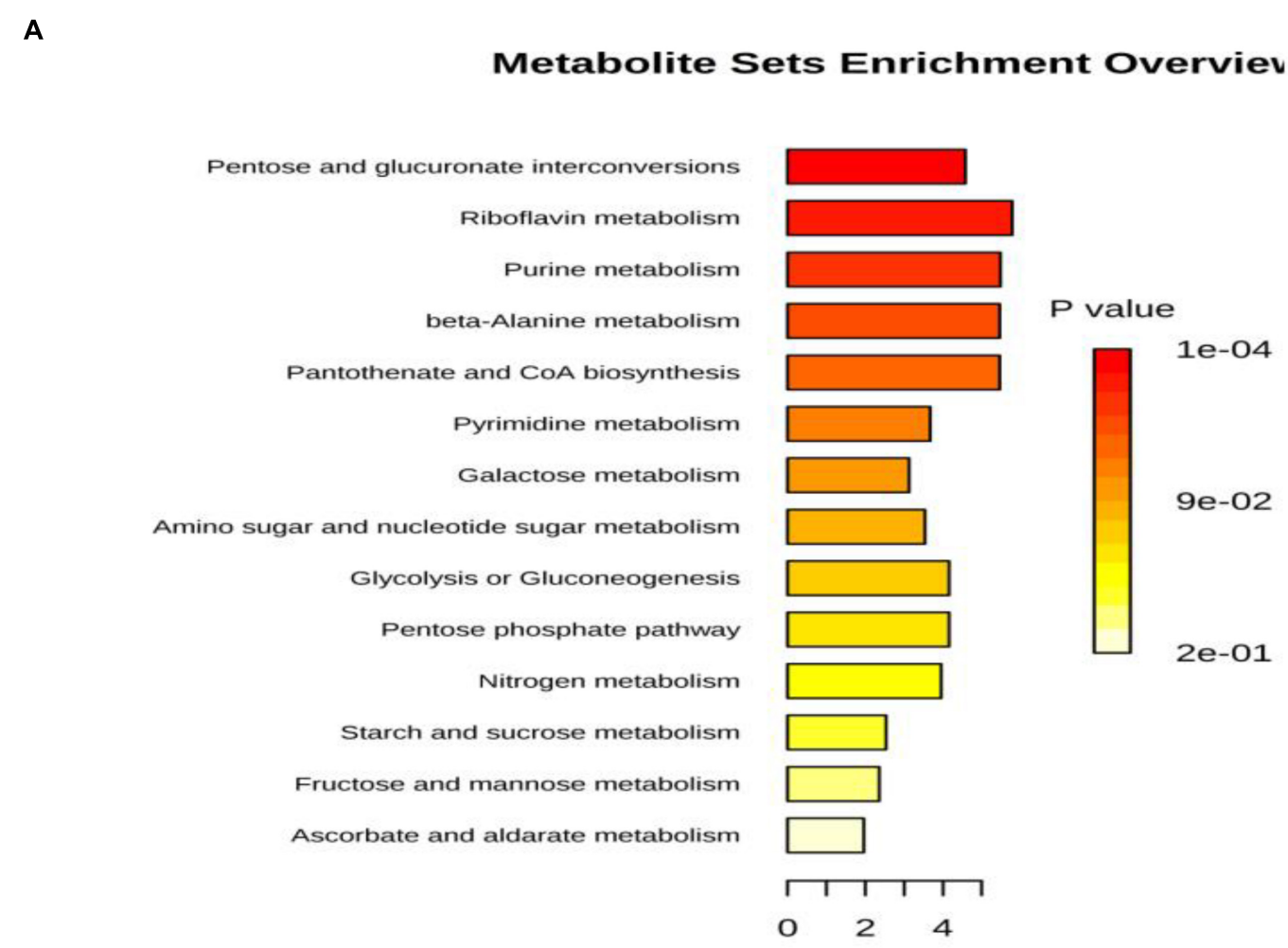

Fold Enrichment

B

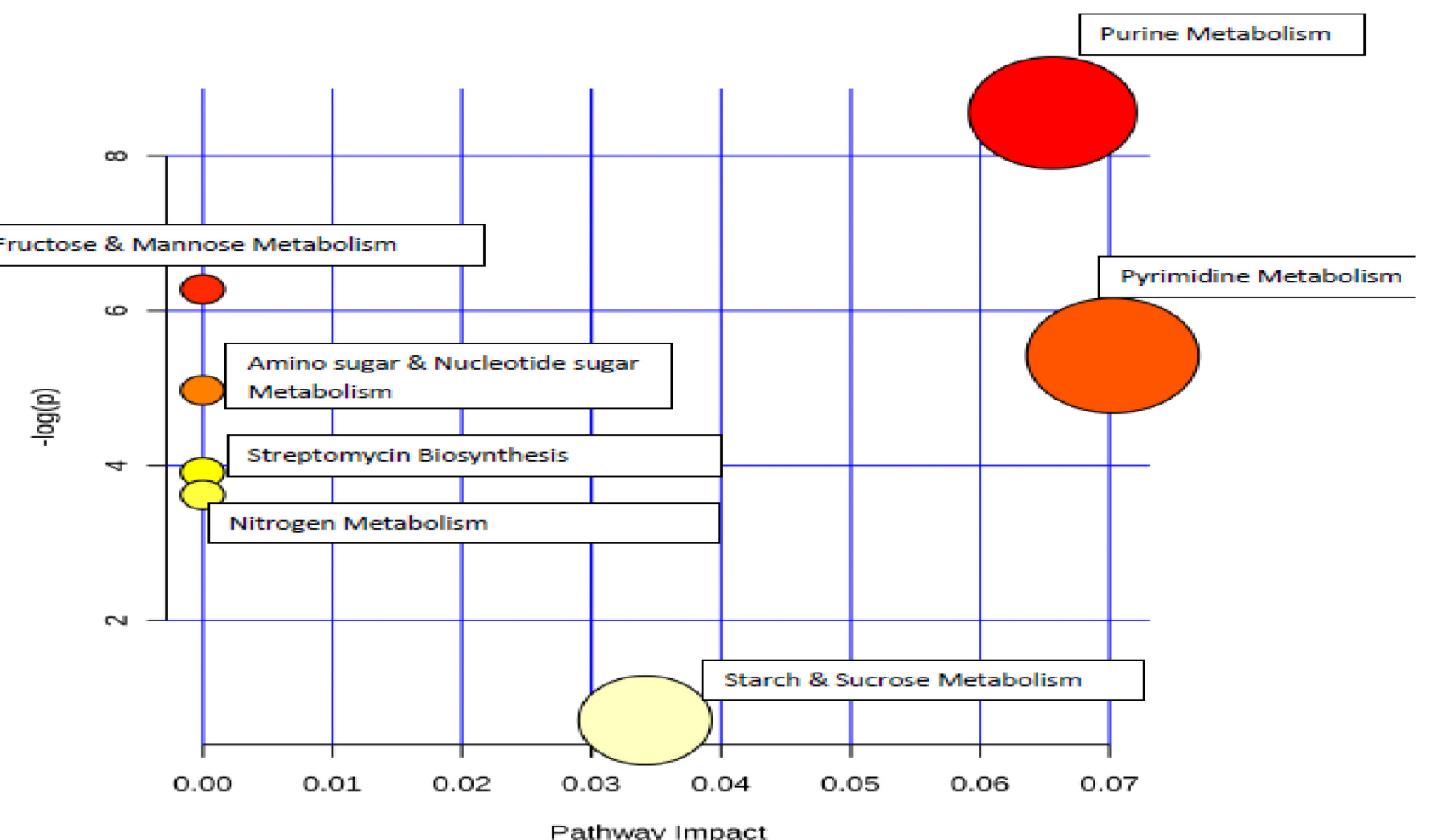

FIGURE 8 | (A) metabolic set enrichment using metabolite concentrations showing the most altered pathways in elevated $\mathrm{NaCl}$ (5\%). (B) pathway impact analysis. All the matched pathways are shown as circles. The color and size of each circle is based on $p$-value and pathway impact value, respectively. Colors of the circle based on $p$-values. The darker colors indicate more significant changes of the pathways $(p<0.05)$. 
of this study. Recently, it has been shown that considerable alterations in amino acid composition during incubation with additional 5\% $\mathrm{NaCl}$ (Alreshidi et al., 2016, 2019), which may explain the up-regulation of nucleotide bases in this study. It has been reported that $E$. coli required producing purine and pyrimidine bases to induce infections in the mouse intestine (Vogel-Scheel et al., 2010).

The changes metabolic profiles observed in this study could indicate the existence of a phenotypic shift that can occur within a mixture of populations (Alreshidi et al., 2013). The phenotypic shifts in bacterial cells and colonies such as SCVs has been previously demonstrated following exposure to various environmental parameters including osmotic and cold stresses (Onyango et al., 2012, 2013; Crompton et al., 2014). Earlier studies have shown that SCVs have slower generation times, reduced release of virulence factors and are found to be auxotrophic for hemin and menadione compounds (Von Eiff, 2008; Proctor et al., 2014; Bui et al., 2015). Thus, it has been suggested, that bacterial cells persistently detect and respond to stress conditions by establishing the most effective and efficient phenotypes for survival. SCVs are highly associated with biofilm formation. These two lifestyles of $S$. aureus represent a very robust protective and adaptive mechanism in response to environmental threats. Metabolic studies have demonstrated a strong relationship between biofilm formation and metabolite changes. For example, it has been indicated that polysaccharide intercellular adhesin (PIA) production in biofilm is regulated by tricarboxylic acid cycle components (Sadykov et al., 2010) and the osmotic stress stimulates biofilm formation (Knobloch et al., 2001; Oniciuc et al., 2016). Several metabolites associated with purine and pyrimidine catabolism were reported to significantly contribute to distinguishing between planktonic and biofilm cells (Liebeke et al., 2011; Ammons et al., 2014). It has also been shown that the uptake of purine bases were highly necessary for biofilm formation (Zhu et al., 2007). This may explain the significant up-regulation of purine and pyrimidine nucleotides under conditions of osmotic stress in this study.

\section{CONCLUSION}

The detection of cytoplasmic metabolites that differentiate between control and treatment samples may help in controlling

\section{REFERENCES}

Adnan, M., Morton, G., and Hadi, S. (2011). Analysis of rpoS and bolA gene expression under various stress-induced environments in planktonic and biofilm phase using 2(-DeltaDeltaCT) method. Mol. Cell. Biochem. 357, 275282. doi: 10.1007/s11010-011-0898-y

Alreshidi, M. M., Dunstan, R. H., Gottfries, J., Macdonald, M. M., Crompton, M. J., Williamson, N. A., et al. (2016). Changes in the cytoplasmic composition of amino acids and proteins observed in staphylococcus aureus during growth under variable growth conditions representative of the human wound site. PLoS ONE 11:e0159662. doi: 10.1371/journal.pone.0159662

Alreshidi, M. M., Dunstan, R. H., Macdonald, M. M., and Roberts, T. K. (2020). The uptake and release of amino acids by Staphylococcus aureus at mid-exponential and stationary phases and their corresponding responses to changes in temperature, $\mathrm{pH}$ and osmolality. Front. Microbiol. 10:3059. doi: $10.3389 /$ fmicb.2019.03059
S. aureus adaptation and survival. Indeed, the outcomes of this study indicated that the incubation of $S$. aureus with both cold and osmotic treatments led to significant variations in the cytoplasmic metabolite composition. Exposing the bacteria to lower temperature of $4^{\circ} \mathrm{C}$ resulted in a significant reduction in the majority of analyzed metabolites, whereas the cells incubated with elevated $\mathrm{NaCl}$ conditions had increased levels of identified metabolites. It is evident that certain strategies were developed to ensure survival during the incubation in low temperature and elevated $\mathrm{NaCl}$ to obtain optimal metabolism status by altering metabolite levels. It was thus concluded that these adjustments in metabolite levels may have assisted this bacterium to survive alterations in environmental conditions. More knowledge of adaptability and survival capability of $S$. aureus under various stress conditions may lead to a better understanding of sterilization methods and food storage as well as control of infection.

\section{DATA AVAILABILITY STATEMENT}

The raw data supporting the conclusions of this manuscript will be made available by the authors, without undue reservation, to any qualified researcher.

\section{AUTHOR CONTRIBUTIONS}

MA designed the experiments, acquired data, analyzed and interpreted data and has written the manuscript.

\section{FUNDING}

This work was supported by the University of Ha'il (grant No. 160984).

\section{ACKNOWLEDGMENTS}

I would like to thank Prof. Hugh Dunstan and Prof. Tim Roberts for their supports, ideas and suggestions.

Alreshidi, M. M., Dunstan, R. H., Macdonald, M. M., Smith, N. D., Gottfries, J., and Roberts, T. K. (2015). Metabolomic and proteomic responses of Staphylococcus aureus to prolonged cold stress. J. Proteomics 121, 44-55. doi: 10.1016/j.jprot. 2015.03.010

Alreshidi, M. M., Dunstan, R. H., Macdonald, M. M., Smith, N. D., Gottfries, J., and Roberts, T. K. (2019). Amino acids and proteomic acclimation of Staphylococcus aureus when incubated in a defined minimal medium supplemented with $5 \%$ sodium chloride. Microbiologyopen 8:e0772. doi: 10.1002/mbo3.772

Alreshidi, M. M., Dunstan, R. H., Onyango, L. A., and Roberts, T. K. (2013). "Staphylococcal phenomics: metabolomic and proteomic responses to environmental stessors," in Microbial Pathogens and Strategies for Combating Them: Science, Technology and Education, ed. A. Mendez-Vilas, (Badajoz: Spain Formatex Research Center).

Ammons, M. C., Tripet, B. P., Carlson, R. P., Kirker, K. R., Gross, M. A., Stanisich, J. J., et al. (2014). Quantitative NMR metabolite profiling of methicillinresistant and methicillin-susceptible Staphylococcus aureus discriminates 
between biofilm and planktonic phenotypes. J. Proteome Res. 13, 2973-2985. doi: $10.1021 / \mathrm{pr} 500120 \mathrm{c}$

Arciola, C. R., Campoccia, D., and Montanaro, L. (2002). Detection of biofilmforming strains of Staphylococcus epidermidis and S. aureus. Expert Rev. Mol. Diagn 2, 478-484.

Brown, G. K., Martin, A. R., Roberts, T. K., and Aitken, R. J. (2001). Detection of ehrlichia platys in dogs in Australia. Aust. Vet. J. 79, 554-558. doi: 10.1111/j. 1751-0813.2001.tb10747.x

Bui, L. M., Turnidge, J. D., and Kidd, S. P. (2015). The induction of Staphylococcus aureus biofilm formation or Small Colony Variants is a strain-specific response to host-generated chemical stresses. Microbes Infect. 17, 77-82. doi: 10.1016/j. micinf.2014.09.009

Burgess, C. M., Gianotti, A., Gruzdev, N., Holah, J., Knochel, S., Lehner, A., et al. (2016). The response of foodborne pathogens to osmotic and desiccation stresses in the food chain. Int. J. Food Microbiol. 221, 37-53. doi: 10.1016/j. ijfoodmicro.2015.12.014

Butt, H. L., Dunstan, R. H., Mcgregor, N. R., Roberts, T. K., Zerbes, M., and Klineberg, I. J. (1998). An association of membrane-damaging toxins from coagulase-negative staphylococci and chronic orofacial muscle pain. J. Med. Microbiol. 47, 577-584. doi: 10.1099/00222615-47-7-577

Calmes, B., Guillemette, T., Teyssier, L., Siegler, B., Pigne, S., Landreau, A., et al. (2013). Role of mannitol metabolism in the pathogenicity of the necrotrophic fungus Alternaria brassicicola. Front. Plant Sci. 4:131. doi: 10.3389/fpls.2013. 00131

Carrera, M., Bohme, K., Gallardo, J. M., Barros-Velazquez, J., Canas, B., and CaloMata, P. (2017). Characterization of foodborne strains of Staphylococcus aureus by shotgun proteomics: functional networks, virulence factors and speciesspecific peptide biomarkers. Front. Microbiol. 8:2458. doi: 10.3389/fmicb.2017. 02458

Chanda, P. K., Bandhu, A., Jana, B., Mondal, R., Ganguly, T., Sau, K., et al. (2010). Characterization of an unusual cold shock protein from Staphylococcus aureus. J. Basic Microbiol. 50, 519-526.

Chaturvedi, V., Flynn, T., Niehaus, W. G., and Wong, B. (1996). Stress tolerance and pathogenic potential of a mannitol mutant of Cryptococcus neoformans. Microbiology 142(Pt 4), 937-943. doi: 10.1099/00221287-1424-937

Crompton, M. J., Dunstan, R. H., Macdonald, M. M., Gottfries, J., Von Eiff, C., and Roberts, T. K. (2014). Small changes in environmental parameters lead to alterations in antibiotic resistance, cell morphology and membrane fatty acid composition in Staphylococcus lugdunensis. PLoS ONE 9:e92296. doi: 10.1371/ journal.pone.0092296

Csonka, L. N. (1989). Physiological and genetic responses of bacteria to osmotic stress. Microbiol. Rev. 53, 121-147. doi: 10.1128/mmbr.53.1.121-147.1989

Dorries, K., and Lalk, M. (2013). Metabolic footprint analysis uncovers strain specific overflow metabolism and D-isoleucine production of Staphylococcus aureus COL and HG001. PLOS ONE 8:e81500. doi: 10.1371/journal.pone. 0081500

Dubois-Brissonnet, F., Trotier, E., and Briandet, R. (2016). The biofilm lifestyle involves an increase in bacterial membrane saturated fatty acids. Front. Microbiol. 7:1673. doi: 10.3389/fmicb.2016.01673

Edwards, K. G., Blumenthal, H. J., Khan, M., and Slodki, M. E. (1981). Intracellular mannitol, a product of glucose metabolism in staphylococci. J. Bacteriol. 146, 1020-1029. doi: 10.1128/jb.146.3.1020-1029.1981

Haste, N. M., Thienphrapa, W., Tran, D. N., Loesgen, S., Sun, P., Nam, S. J., et al. (2012). Activity of the thiopeptide antibiotic nosiheptide against contemporary strains of methicillin-resistant Staphylococcus aureus. J. Antibiot. (Tokyo) 65, 593-598. doi: 10.1038/ja.2012.77

Jongerius, I., Köckritz-Blickwede, M. V., Horsburgh, M. J., Ruyken, M., Nizet, V., and Rooijakkers, S. H. M. (2012). Staphylococcus aureus virulence is enhanced by secreted factors that block innate immune defenses. Innate Immun. 4, 301-311. doi: 10.1159/000334604

Kenny, J. G., Moran, J., Kolar, S. L., Ulanov, A., Li, Z., Shaw, L. N., et al. (2013). Mannitol utilisation is required for protection of Staphylococcus aureus from human skin antimicrobial fatty acids. PLoS ONE 8:e67698. doi: 10.1371/journal. pone. 0067698

Kets, E. P., Galinski, E. A., De Wit, M., De Bont, J. A., and Heipieper, H. J. (1996). Mannitol, a novel bacterial compatible solute in Pseudomonas putida S12. J. Bacteriol. 178, 6665-6670. doi: 10.1128/jb.178.23.6665-6670.1996
Kilstrup, M., Hammer, K., Ruhdal Jensen, P., and Martinussen, J. (2005). Nucleotide metabolism and its control in lactic acid bacteria. FEMS Microbiol. Rev. 29, 555-590. doi: 10.1016/j.fmrre.2005.04.006

Knobloch, J. K., Bartscht, K., Sabottke, A., Rohde, H., Feucht, H. H., and Mack, D. (2001). Biofilm formation by Staphylococcus epidermidis depends on functional RsbU, an activator of the sigB operon: differential activation mechanisms due to ethanol and salt stress. J. Bacteriol. 183, 2624-2633. doi: 10.1128/jb.183.8.26242633.2001

Liebeke, M., Dorries, K., Zuhlke, D., Bernhardt, J., Fuchs, S., Pane-Farre, J., et al. (2011). A metabolomics and proteomics study of the adaptation of Staphylococcus aureus to glucose starvation. Mol. Biosyst. 7, 1241-1253.

Mirani, Z. A., Aziz, M., and Khan, S. I. (2015). Small colony variants have a major role in stability and persistence of Staphylococcus aureus biofilms. J. Antibiot. (Tokyo) 68, 98-105.

Murphy, G. R., Dunstan, R. H., Macdonald, M. M., Gottfries, J., and Roberts, T. K. (2018). Alterations in amino acid metabolism during growth by Staphylococcus aureus following exposure to $\mathrm{H} 2 \mathrm{O} 2$ - A multifactorial approach. Heliyon 4:e00620.

Mykytczuk, N. C., Trevors, J. T., Leduc, L. G., and Ferroni, G. D. (2007). Fluorescence polarization in studies of bacterial cytoplasmic membrane fluidity under environmental stress. Prog. Biophys. Mol. Biol. 95, 60-82. doi: 10.1016/j. pbiomolbio.2007.05.001

Nguyen, T., Kim, T., Ta, H. M., Yeo, W. S., Choi, J., Mizar, P., et al. (2019). Targeting mannitol metabolism as an alternative antimicrobial strategy based on the structure-function study of mannitol-1-phosphate dehydrogenase in Staphylococcus aureus. MBio 10:e2660-18.

Oniciuc, E. A., Cerca, N., and Nicolau, A. I. (2016). Compositional analysis of biofilms formed by staphylococcus aureus isolated from food sources. Front. Microbiol. 7:390. doi: 10.3389/fmicb.2016.00390

Onyango, L. A., Dunstan, R. H., Gottfries, J., Von Eiff, C., and Roberts, T. K. (2012). Effect of low temperature on growth and ultra-structure of Staphylococcus spp. PLoS ONE 7:e29031. doi: 10.1371/journal.pone.0029031

Onyango, L. A., Hugh Dunstan, R., Roberts, T. K., Macdonald, M. M., and Gottfries, J. (2013). Phenotypic variants of staphylococci and their underlying population distributions following exposure to stress. PLoS ONE 8:e77614. doi: 10.1371/journal.pone.0077614

Phadtare, S. (2004). Recent developments in bacterial cold-shock response. Curr. Issues Mol. Biol 6, 125-136.

Proctor, R. A., Kriegeskorte, A., Kahl, B. C., Becker, K., Loffler, B., and Peters, G. (2014). Staphylococcus aureus small colony variants (SCVs): a road map for the metabolic pathways involved in persistent infections. Front. Cell Infect. Microbiol. 4:99. doi: 10.3389/fcimb.2014.00099

Sadykov, M. R., Zhang, B., Halouska, S., Nelson, J. L., Kreimer, L. W., Zhu, Y., et al. (2010). Using NMR metabolomics to investigate tricarboxylic acid cycledependent signal transduction in Staphylococcus epidermidis. J. Biol. Chem. 285, 36616-36624. doi: 10.1074/jbc.m110.152843

Sand, M., Mingote, A. I., Santos, H., Muller, V., and Averhoff, B. (2013). Mannitol, a compatible solute synthesized by Acinetobacter baylyi in a two-step pathway including a salt-induced and salt-dependent mannitol-1-phosphate dehydrogenase. Environ. Microbiol. 15, 2187-2197. doi: 10.1111/1462-2920. 12090

Shebuski, J. R., Vilhelmsson, O., and Miller, K. J. (2000). Effects of growth at low water activity on the thermal tolerance of Staphylococcus aureus. J. Food Prot. 63, 1277-1281. doi: 10.4315/0362-028x-63.9.1277

Singh, R., Ray, P., Das, A., and Sharma, M. (2010). Enhanced production of exopolysaccharide matrix and biofilm by a menadione-auxotrophic Staphylococcus aureus small-colony variant. J. Med. Microbiol. 59, 521-527. doi: 10.1099/jmm.0.017046-0

Tuchscherr, L., Heitmann, V., Hussain, M., Viemann, D., Roth, J., Von Eiff, C., et al. (2010). Staphylococcus aureus small-colony variants are adapted phenotypes for intracellular persistence. J. Infectious Dis. 202, 1031-1040. doi: 10.1086/656047

Vandecasteele, S. J., Peetermans, W. E., Carbonez, A., and Van Eldere, J. (2004). Metabolic activity of Staphylococcus epidermidis is high during initial and low during late experimental foreign-body infection. J. Bacteriol. 186, 2236-2239. doi: 10.1128/jb.186.8.2236-2239.2004

Vilhelmsson, O., and Miller, K. J. (2002a). Humectant permeability influences growth and compatible solute uptake by Staphylococcus aureus subjected to osmotic stress. J. Food Prot. 65, 1008-1015. doi: 10.4315/0362-028x-65.6.1008 
Vilhelmsson, O., and Miller, K. J. (2002b). Synthesis of pyruvate dehydrogenase in Staphylococcus aureus is stimulated by osmotic stress. Appl. Environ. Microbiol. 68, 2353-2358. doi: 10.1128/aem.68.5.2353-2358. 2002

Vogel-Scheel, J., Alpert, C., Engst, W., Loh, G., and Blaut, M. (2010). Requirement of purine and pyrimidine synthesis for colonization of the mouse intestine by Escherichia coli. Appl. Environ. Microbiol. 76, 5181-5187. doi: 10.1128/aem. 00242-10

Von Eiff, C. (2008). Staphylococcus aureus small colony variants: a challenge to microbiologists and clinicians. Int. J. Antimicrob. Agents 31, 507-510. doi: 10. 1016/j.ijantimicag.2007.10.026

Watanabe, S., Matsumoto, M., Hakomori, Y., Takagi, H., Shimada, H., and Sakamoto, A. (2014). The purine metabolite allantoin enhances abiotic stress tolerance through synergistic activation of abscisic acid metabolism. Plant Cell Environ. 37, 1022-1036. doi: 10.1111/pce.12218

Xia, J., Psychogios, N., Young, N., and Wishart, D. S. (2009). MetaboAnalyst: a web server for metabolomic data analysis and interpretation. Nucleic Acids Res. 37, W652-W660.
Zahid, N., Schweiger, P., Galinski, E., and Deppenmeier, U. (2015). Identification of mannitol as compatible solute in Gluconobacter oxydans. Appl. Microbiol. Biotechnol. 99, 5511-5521. doi: 10.1007/s00253-015-6626-x

Zhu, Y., Weiss, E. C., Otto, M., Fey, P. D., Smeltzer, M. S., and Somerville, G. A. (2007). Staphylococcus aureus biofilm metabolism and the influence of arginine on polysaccharide intercellular adhesin synthesis, biofilm formation, and pathogenesis. Infect. Immun. 75, 4219-4226. doi: 10.1128/iai.00509-07

Conflict of Interest: The author declares that the research was conducted in the absence of any commercial or financial relationships that could be construed as a potential conflict of interest.

Copyright (C) 2020 Alreshidi. This is an open-access article distributed under the terms of the Creative Commons Attribution License (CC BY). The use, distribution or reproduction in other forums is permitted, provided the original author(s) and the copyright owner(s) are credited and that the original publication in this journal is cited, in accordance with accepted academic practice. No use, distribution or reproduction is permitted which does not comply with these terms. 